University of Nebraska - Lincoln

DigitalCommons@University of Nebraska - Lincoln

Faculty Publications: Department of Teaching, Department of Teaching, Learning and Teacher Learning and Teacher Education

Education

2021

Dance as dialog: A metaphor analysis on the development of interculturality through arts and community-based learning with preservice teachers and a local refugee community

Theresa Catalano

Uma Ganesan

Alessia Barbici Wagner

Jenelle Reeves

Alison E. Leonard

See next page for additional authors

Follow this and additional works at: https://digitalcommons.unl.edu/teachlearnfacpub

Part of the Curriculum and Instruction Commons, and the Teacher Education and Professional Development Commons

This Article is brought to you for free and open access by the Department of Teaching, Learning and Teacher Education at DigitalCommons@University of Nebraska - Lincoln. It has been accepted for inclusion in Faculty Publications: Department of Teaching, Learning and Teacher Education by an authorized administrator of DigitalCommons@University of Nebraska - Lincoln. 


\section{Authors}

Theresa Catalano, Uma Ganesan, Alessia Barbici Wagner, Jenelle Reeves, Alison E. Leonard, and Stephanie Wessels 


\title{
Dance as dialog: \\ A metaphor analysis on the development of interculturality through arts and community-based learning with preservice teachers and a local refugee community
}

\author{
Theresa Catalano, ${ }^{1}$ Uma Ganesan, ${ }^{2}$ \\ Alessia Barbici-Wagner, ${ }^{3}$ Jenelle Reeves, ${ }^{4}$ \\ Alison E. Leonard, 5 \& Stephanie Wessels ${ }^{6}$
}

1 University of Nebraska-Lincoln, Department of Teaching, Learning and Teacher Education, 27 Henzlik Hall, Lincoln, NE, 68588, USA

2 University of Nebraska-Lincoln, Department of Teaching, Learning and Teacher Education, 23 Henzlik Hall, Lincoln, NE, 68588, USA

3 University of Nebraska-Lincoln, Department of Teaching, Learning and Teacher Education, 22 Henzlik Hall, Lincoln, NE, 68588, USA

4 University of Nebraska-Lincoln, Department of Teaching, Learning and

Teacher Education, 44C Henzlik Hall, Lincoln, NE, 68588, USA

5 Clemson University, Department of Teaching and Learning, 409 A Gantt

Circle, Clemson, SC, 29634, USA

6 University of Nebraska-Lincoln, Department of Teaching, Learning and

Teacher Education, 61C Henzlik Hall, Lincoln, NE, 68588, USA

Corresponding author - T. Catalano, 27 Henzlik Hall, Lincoln, NE, 68588, USA.

E-mail addresses: tcatalano2@unl.edu (T. Catalano), uganesan2@huskers.unl.edu (U. Ganesan), abarbici-wagner2@huskers.unl.edu (A. Barbici-Wagner), jreeves2@ unl.edu (J. Reeves),

aleona2@clemson.edu (A.E. Leonard), swessels2@unl.edu (S. Wessels).

Published in Teaching and Teacher Education 104 (2021) 103369

doi:10.1016/j.tate.2021.103369

Copyright / (C) 2021 Elsevier Ltd. Used by permission.

Submitted 25 July 2020; revised 26 February 2021; accepted 19 April 2021; published 10

May 2021. 


\begin{abstract}
This paper explores the use of arts and community-based (ACB) approaches to intercultural teacher education. Twenty-four preservice teachers and five adult Yazidi refugees/community members participated in this study which involved a two-week arts-based workshop in Fall 2019 at the University of Nebraska-Lincoln. Data for the study included pre- and post-group discussion recordings as well as oral and written reflections one week after the workshop. Using metaphor analysis, the authors examine the way project participants talk about their experiences in the workshop. Findings showed how ACB approaches hold promise as a vehicle for developing interculturality in teacher education.
\end{abstract}

Keywords: Metaphor analysis, Preservice teacher education, Arts and communitybased (ACB) education

\title{
Highlights
}

- Arts and community-based (ACB) approach to intercultural teacher education.

- Preservice teachers and Yazidi refugees engaged in an arts-based intervention.

- Co-creation and performance of dance stories based on immigration experiences.

- Metaphor analysis reveals ways in which ACB aids in developing interculturality.

\section{Introduction}

Addressing the needs of marginalized youth, their families and communities during teacher preparation is an imperative, and teacher educators are working to prepare preservice teachers to work in respectful ways with students and their families while being culturally and linguistically responsive (e.g., Gay, 2010; Ladson-Billings, 2009; Zeichner, Bowman, Guillen, \& Napolitan, 2016). Increased globalization (Perry \& Southwell, 2011), among other factors has resulted in an increase of students with immigrant backgrounds in classrooms worldwide. Yet, many teachers are still new to the experience of teaching immigrant-background students (Bigelow, 2018). Further, the recent strides in preparing teachers for multilingual classrooms have focused mainly on linguistic interventions. While making instruction linguistically comprehensible is critical, there remains a pressing need to foster and maintain intercultural understanding and competence in the teaching force (Catalano, Reeves, \& Wessels, 2018)

As part of culturally responsive preparation, teacher learners must develop interculturality, which is the ability to interact appropriately (and effectively) in situations where multiple cultures are present (Bennett, 2008; Deardorff, 2006; Lustig, Koester, \& Halualani, 
2006). Interculturality also entails constructing relations between cultures that "enable groups and individuals who belong to such cultures within a single society or geo-political entity to forge links based on equity and mutual respect" (Leclerq, 2003, p. 9). For good intercultural education to occur in teacher education programs, at least two shifts in the way programs approach intercultural education need to occur (Gorski, 2008). First, having cultural awareness is not enough. We must avoid "the sorts of cultural awareness activities that other or essentialize nondominant groups or that, absent a commitment to social justice, require dominated groups to make themselves ever more vulnerable for the educational benefit of the privileged" (Gorski, 2008, p. 522). Second, we must engage teacher learners in activities that "acknowledge power imbalances" (Gorski, 2008, p. 523) while avoiding placing the burden of such activities on oppressed populations themselves. Teacher education for interculturality, therefore, is complex work.

Two approaches in teacher education that hold promise for building teacher learners' interculturality are arts-based and communitybased education. There is a long tradition of integrating the arts in teacher education (Dewey, 1934/2005; Powers \& Duffy, 2016), and recent research on community-based projects is emerging (e.g., Sharkey, Clavijo-Olarte, \& Ramirez, 2016; Zeichner, Payne, \& Brayko, 2015). Using the methodology of metaphor analysis, we will explore these two approaches as one: arts and community-based (ACB) education recognizing that often, the two are merged, as in our study. Our research was guided by the following questions:

1. How might ACB approaches aid in developing interculturality of preservice teachers (aka teacher learners)?

2. What can metaphor analysis contribute to the understanding of developing interculturality in teacher learners?

To answer our questions, we implemented a two-week ACB workshop in an undergraduate course for preservice secondary teachers in partnership with local Yazidi refugees in the midwestern United States. The preservice teachers, research team, and Yazidi collaborators participated in all parts of the workshop including a museum exhibition activity, pre- and post-group discussions, and the creation of dance 
stories based on these experiences. Data for the study included the pre- and post-group discussion recordings as well as oral and written reflections one week after the workshop (see more about this in our Data Collection/ Analysis sections). The next section reviews similar studies that have examined the role of the arts and communities in teacher education.

\section{Arts and community-based (ACB) approaches and teacher education}

John Dewey was one of the first to highlight the role of the arts in enhancing perception and meaning making (Dewey, 1934/2005, p. 304). A number of recent studies have added to our understanding of the value of arts-based approaches in teacher education, particularly to address social justice concerns and, potentially, to develop teachers' interculturality by deepening teachers' understanding of cultural groups. These studies show how ACB approaches aid preservice teachers to dispel stereotypes, confront xenophobia, and lessen marginalization (Hajisoteriou \& Angelides, 2017; Powers \& Duffy, 2016).

Toward deepening teachers' understanding of cultural groups, Powers and Duffy (2016) found their arts-based initiative utilizing Augusto Boal's Theater of the Oppressed to provide "a powerful framework for students to recognize, confront, and challenge beliefs about themselves and the multiple identities of their future students" ( $p$. 71). O'Farrell (2015) points to the important role that arts-based education has as a bridge to intercultural understanding. He focuses on applying arts principles and practices as a tool to social cohesion and intercultural dialog (p. 372). One way this is proposed is to bring people from different cultural groups together in the art-making process while taking care that the "process of building bridges between cultures does not lead to the denigration of either culture nor to the endangerment of participants" (O'Farrell, 2015, p. 376).

Arts-based initiatives have also encouraged democratic deliberation and civil discourse, particularly through collaborative artmaking (Catalano \& Leonard, 2016; Hajisoteriou \& Angelides, 2017). Catalano and Leonard (2016) explored the capacity that dance and movement bring to discussion of controversial topics in divisive times, particularly 
when immigrants/refugees are vilified or marginalized by powerful members of society for political purposes. They also aimed to understand how dance can be integrated into the curriculum to prepare students to engage in democratic deliberation of topics such as immigration. They found that not only did dance provide a way to build community among students, allowing for trust and open discussions on difficult subjects, it embodied democratic ideals in education such as interdependence, creating empathy, valuing diversity, and disrupting ingrained attitudes and ideas. In this way, it helped participants engage in civil dialog and learn "how to live together" (Catalano \& Leonard, 2016).

In these arts-based initiatives, students were sometimes made uncomfortable. While acknowledging that some discomfort has to occur in order for students to disrupt ingrained ways of thinking, Powers and Duffy (2016) found that teacher educators doing art-based activities that push students to re-examine assumptions and beliefs need to work to create 'safe enough spaces' where "students can grapple with the complexity of teaching and learning, so that they can develop the skills, dispositions, and knowledge to serve all children" (p. 71).

John Dewey (1956/1990) was among the first educational scholars calling for schools to be understood as an extension of the larger community (1956/1990). He noted, "When the school introduces and trains each child of society into membership within such a little community, saturating him with the spirit of service and providing him with the instruments of effective self-direction, we shall have the deepest and best guarantee of a larger society which is worthy, lovely, and harmonious" (Dewey, 1990, p. 22). Research on community-based projects has also illustrated the "power and potential of the arts in transforming communities and impacting positive changes which creatively address critical challenges of our times" (Leong, 2014, p. 283). For example, Cooper (2007) describes ways that preservice teachers responded to community-based activities through analysis of work samples, interviews, and observations. The author found that the preservice teachers' stereotypical beliefs about their learners' communities were challenged, and in the process, they discovered new strengths of their students and families. Findings point to the value of community cultural-immersion activities in helping preservice teachers "correct misperceptions about, but also build relationships with their 
learners that can potentially impact student achievement” (p. 245). Using Social Justice Teacher Education (SJTE) as a framework, Sharkey, Clavijo-Olarte, and Ramirez (2016) worked with local teachers in Bogotá, Colombia to find out "how teachers develop, implement, and interpret community-based pedagogies (CBPs)" (p. 306). The authors found that the school-university partnership reinforced their commitment "to working with teachers in their contexts as co-creators of knowledge and co-investigators in pursuing pressing issues, and to SJTE as collaborative effort" (p. 317).

Similarly, Zeichner et al. (2015) discovered that when teacher candidates participate in activities outside of schools, "they can encounter and engage with different perspectives and forms of knowledge than those they typically accessed in school- and university-based spaces (e.g., Gonzalez, Moll, \& Amanti, 2005)" (p. 128). In their study on a Community Teaching Strand, Zeichner et al. (2016) found "there is a big difference between reading something or discussing complex and sensitive issues with a professor and hearing it and discussing it with community mentors" (p. 286) and hence community-based projects have potential for changing attitudes of teacher learners.

Just as the Theater of the Oppressed "uses physical embodiments, sounds, words, and imagination to crystallize an issue with an eye toward transforming it" (Powers \& Duffy, 2016, p. 62), and involves a community coming together to create "an improvisational forum that uncovers and explores shared ideas and concerns", this study aims to use an ACB approach-using visual arts and dance-to do the same. We now turn to our conceptual framework.

\section{Conceptual framework}

\subsection{Social Justice Teacher Education (SJTE) and culturally relevant} arts education (CRAE)

Social Justice Teacher Education (SJTE) aims to "reduce the inequities that exist in educational experiences and opportunities afforded to students, acknowledging the impacts that poverty, race, language, geography, and im/migration have on the asymmetrical distribution of resources and access to services (Nieto, 2000; Zeichner, 2011)" 
(Sharkey, Clavijo-Olarte, \& Ramírez, 2016, p. 307). SJTE takes a "collaborative, collective, and situated approach to addressing these inequities" while at the same time "valuing the knowledge, skills, and perspectives that all community members bring to these challenges (Cochran-Smith \& Lytle, 2009; Zeichner, 2011)" (Sharkey et al., 2016, p. 307).

In achieving these goals, researchers have found that it is important to "figure out ways to engage and work in solidarity with local communities" (Zeichner et al., 2016, p. 288). According to Calabrese-Barton, Tan, and Birmingham (2020) in order for teaching to be justice oriented, it must "address the ways in which historicized injustices manifest in systems of power that play out in local classroom practice as part of disciplinary-based teaching and learning" (p. 2). Highleverage practices that restructure power relations in classrooms and intersect with historicized injustice help support teachers in learning about their students. Justice-oriented teaching and learning must also be equitable (i.e., it expands opportunities for learning) and consequential (i.e., it promotes social transformations), and it must show "how normative power relations are disrupted" (Calabrese-Barton et al., 2020, p. 17). Justice-oriented teaching also "foregrounds the political and humanizing dimensions of teaching/learning" (which we would like to point out meshes well with the goals of ACB learning), and it helps students develop critical awareness of and strategies for future social change (p. 3).

Culturally relevant arts education (CRAE) for social justice (Hanley, 2013) combines social justice education with the arts. CRAE incorporates theories from a variety of fields such as multicultural education, critical pedagogy, contextual teaching and learning with arts production, and integration aesthetics, which "involves an immersion in the experiences and perspectives of the world of arts and artists" (Hanley, 2013, p. 8). To achieve the goals of CRAE, one must focus on the "generative imagination and creativity of the learner" (p. 9). The ultimate goal is "to promote empowerment so that all individuals can assert their inherent creativity to recreate a world that shares, recognizes, and includes their gifts" (p. 9). Hence, arts-based inquiry can provide "creative, imaginative, participatory, and action-oriented approaches to examining a range of issues related to social and economic justice" (Osei-Kofi, 2013, p. 138). 
CRAE is different from ACB in that it is centered in arts education whereas ACB integrates the arts into other content areas (in our case, teacher education coursework centered on working with immigrant populations) but also, ACB combines SJTE's emphasis on working with local communities. Hence, ACB utilizes the frameworks of both CRAE and SJTE to explore the value of arts and community-based learning in teacher education. The next section explains our methodology of metaphor analysis, its roots in cognitive linguistics, and its connection to educational research.

\subsection{Metaphor analysis and education}

Most of us know metaphor as the process of comparing two things that are alike in one important way. For example, we might say that children are flowers, because they grow so fast and are so lovely. However, in the field of cognitive linguistics, which studies the relationship between language and thought, metaphor is much more than a rhetorical trope. Metaphor, as a cognitive process, is a largely unconscious way in which we categorize and understand our world (Lakoff \& Johnson, 1980) and "how we relate to people" (Gatti \& Catalano, 2015, p. 150). Thus, as part of our conceptual system, metaphor "plays a central role in defining our everyday realities" (Lakoff \& Johnson, 1980, p. 3). Metaphors "reflect and connect with the very core schemata of human thought and action and serve as an essential component of communication" (Levin \& Wagner, 2006, p. 237). Metaphors also allow us to express abstract ideas that are difficult to explain because they enable us to communicate "complex configurations of information" and to "capture the richness of a particular experience" more so than using literal language (Levin \& Wagner, 2006, p. 237). Hence, because of their power to reveal our sometimes unconscious sense-making, metaphors have great value in the field of education.

Conceptual blending theory helps us understand better how metaphors work. Conceptual blending is a basic cognitive operation and "a common, everyday process indispensable to the most routine workings of the modern human mind" (Turner, 2014, p. 18). it is an online, dynamic process, meaning that it happens in real time and is not pre-planned. According to this theory, "metaphors are blended spaces that act as places in which cognitive work such as reasoning, 
drawing inferences and developing emotions takes place" (Fauconnier \& Turner, 1996, p. 115). In conceptual blending theory, this cognitive work takes place in a conceptual integration network in the brain. This network involves mental spaces that include a generic space, two input spaces and a blended space (Kok \& Bublitz, 2011). A salient example of how a blending operation (AKA metaphor) works comes from a dance class (adapted from Catalano \& Fielder, 2018, p. 242):

When dance teachers work with young children, they often ask them to stand up 'nice and tall, like a giraffe'. In this case, the generic space is the mental concept of a living being (agent) that stands up (action). Input Space 1 would be a young dancer's body and his or her ability to stretch the neck and stand up tall. Input Space 2 would be a giraffe, which many 4- to 5-year-olds have seen either in photos or at the zoo, and therefore know that it has a long neck and is very tall. The blended space would be when the dancer's body takes on these salient characteristics of a giraffe, namely, being tall and having a long neck. The end result (if done correctly) would be the young dancer standing like a ballet dancer, neck stretched and shoulders back (note, this is not a natural position for most people to hold their bodies).

In the example above, the phrase 'stand up nice and tall like a giraffe' would can be referred to as the linguistic realization of the conceptual metaphor DANCERS ARE GIRAFFES, which allows the children to immediately understand that what the teacher wants is for the students to stretch their necks. In the process of metaphor analysis of spoken or written discourse, people do not always say the actual metaphor, instead, they use words from other semantic domains to make the blend. A good example of this is when we talk about candidates in a political debate and we say something like "The politician attacked his opponent for most of the debate”. The linguistic realization attacked is evidence of the common metaphor POLITICS IS WAR. Even though the word WAR was not mentioned, it is clear that the word attacked is being used metaphorically in this context. We will now turn to a discussion of metaphor analysis as a methodology in educational research. 
Metaphor analysis as a methodology has come a long way, and more recently, many cognitive linguists have found the linguistic metaphor identification process (MIPVU) to be a useful guide (Steen et al., 2010). This process involves first reading the entire text to gain understanding of the meaning, and then determining the lexical units in the text (i.e., attack and defend in the context of an argument). Then for each lexical unit, establish its meaning in context and then determine a more basic contemporary meaning for each lexical unit (e.g., physically attacking or defending someone in a physical fight). If the lexical unit has a more basic or current meaning in context other than the given one, "decide whether the contextual meaning contrasts with the basic meaning but can be understood in comparison with it" (Steen et al., 2010, p. 6). If yes, count it as a metaphor. In the case of the example of attack or defend in the context of an argument, it would be determined metaphorical whereas attack and defend in the context of a physical fight would not be considered metaphor.

We would also like to point out that metaphor analysis involves not just working out what the metaphors are and figuring out which ones are dominant in the text(s). It involves explaining the semantic entailments that come with the metaphors and what the implications of them signify. Catalano (2016) illustrates how this is done in her book on global migration in which one participant talked about how her boss spoke English saying "She, you know, speak ... like a machine gun, then, I-I, like (tatatatatatatata) ... I cannot really have room to, you know,...to say my point" (Catalano, 2016, p. 170). The linguistic realization of "like a machine gun" represented the metaphor LANGUAGE LEARNING IS WAR, but the author also pointed out what the implications of this were for teaching by reminding readers of all the things included in the semantic domain of WAR: violence, guns, blood, injuries, death, destruction, etc. ... If students view language learning as traumatic and terrifying, just as in a war, then they might have troubling learning. Hence, comparing speech to rapid gun fire exposes a need for teachers to slow down their speech but also make students comfortable in the language learning process. Without breaking down this metaphor and all the thinking behind it, a metaphor analysis is incomplete.

Metaphor analysis has been used in teacher education research to reveal self-understandings of teachers as well as teacher identities 
and conceptions of what teaching is (Hunt, 1987; Miller \& Fredericks, 1988; Munby, 1986; Provenzo, McCloskey, Kottkamp, \& Cohn, 1989; Russell \& Johnston, 1988). Many studies have used metaphor analysis to examine the way in which teachers conceive of teaching and learning (e.g., Martínez, Sauleda, \& Huber, 2001; Zheng \& Song, 2010) and other studies have investigated how teachers conceive of the learning to teach process. For example, Bullough (1991) studied three student teachers and the metaphors they used to talk about themselves in the process of learning to teach showing how metaphors such as "teacher as chameleon" revealed a lack of a clear perception of self as teacher, which pointed toward a need for teacher educators to assist with building a "teaching self" before anything else (p. 50). Gatti \& Catalano (2015) studied novice teacher perceptions of the learning to teach process in an Urban Teacher Residency (UTR) exposing conflicting metaphors of LEARNING TO TEACH IS A JOURNEY and LEARNING TO TEACH IS A BUSINESS, which showed how "neoliberal common sense seeps into the learning to teach process" (p. 157). The authors argue for the need to push-back on neoliberal ways of thinking about teacher education.

Besides the above studies which focus on understanding perceptions of teaching and learning, using a variety of methods to elicit metaphors such as language portraits, reflections on experiences, and think-aloud protocols, researchers have also studied the power of metaphor as a teaching tool in the areas of science (Cameron, 2002; Levin \& Wagner, 2006; Niebert, Marsch, \& Treagust, 2012), culture (Ryan, 1996), and language (Coffey, 2015; Zhang \& $\mathrm{Hu}, 2009$, p. 77). In these studies, teachers explicitly used metaphors to help students illuminate and solidify their understandings of various concepts or disciplines, or through elicitation type tasks they studied how teacher learners or learners themselves conceived of various skills or fields. None of the studies we found explored teacher learner conceptions of ACB education and its value in the development of interculturality. Hence, the present study fills this gap by examining emergent discourse of teacher learners and Yazidi collaborators talking about their experiences in the ACB workshop implemented for this study. 


\section{Materials and methods}

\subsection{Research epistemology}

As qualitative researchers, we were influenced by arts practice research (Phelan \& Nunan, 2018) which holds that "artistic practices may be a key component of the research method, a part of the final thesis, or constitute the whole work" (p. 1). In our study, arts practices inspired the creation of the project, the activities project participants ${ }^{1}$ and researchers engaged in, and our use of metaphor analysis. So, while we did categorize and count metaphors students used to talk about their experiences (as we will explain in our data analysis section), we also experienced the art activities along with participants/collaborators, which allowed us to have more context and a deeper and more nuanced understanding of their perceptions of the experiences.

\subsection{Preservice teachers}

Twenty-four preservice teachers in an undergraduate course on teaching multilingual learners in the content areas in Fall 2019 at the University of Nebraska-Lincoln participated in this study. This course focused on preparing future teachers to work with students with immigrant backgrounds in their classes. The preservice teachers took the course as part of their initial certification to teach grades 7-12 in various content areas including Business, Science, English, Special Education, Social Studies, and Spanish. There were seven males and 17 females in the class. The Institutional Review Board (IRB) at our institution approved participant consent, which was solicited by a graduate student at the beginning of the course. Consent forms were collected by the graduate student and placed in concealed envelopes at the beginning of the project and kept by the department administrative secretary. Students were required to participate in the ACB activities as part of regular course requirements, and all project participants gave consent to be part of the study.

1 We use the term project participants to include both Yazidi community members and teacher learners. 


\subsection{Yazidi community in $Y$}

In addition to the students enrolled in the courses described above, five Yazidi community members took part in the study. Yazidis are an ethno-religious group indigenous to Iraq, Syria, and Turkey (among other areas). The city of Lincoln-which is where the University of Nebraska-Lincoln (UNL) is located-is designated as a refugee resettlement area (the fifth largest per capita in the U.S.) (Lincoln, Nebraska Population, 2020). It also boasts the largest Yazidi diaspora in the United States with more than 3000 Yazidis settling there (A Diaspora Is Born in [state], 2017) a number which increased after the 2014 genocide of Yazidi people by ISIS.

Through a partnership with Yazda (a local non-profit whose mission is to prevent future genocides against the Yazidi community and other minorities and to assist them in recovery from the 2014 genocide), professors and graduate students from the Department of Teaching, Learning and Teacher Education helped provided tutoring services, assisted with English and citizenship classes and other small requests from Yazda members. In return, Yazda agreed to help recruit five community members (one to work with each group of 4-5 preservice teachers) to be part of this study. The IRB approved participant consent for Yazda members and with the help of her former student, First Author was able to recruit five Yazidis ( 2 men and 3 women) to be part of the study. Consent forms were distributed by the First Author upon their first informational meeting at which they learned about the arts-based workshops and the study's aims. Yazidi collaborators were informed of the study's goals of preparing teachers better to work with immigrant-background students like their own children, and they were given a modest honorarium for their participation in the activities which was distributed one week after the workshops when Yazidi collaborators met with First Author to reflect orally on their experiences.

\subsection{Researcher positionality}

The research team consisted of four professors and two graduate students (all co-authors of this paper). Three of the professors are colleagues in the Department of Teaching, Learning and Teacher 
Education at UNL (all White females) specializing in preparing teachers to work with students with immigrant backgrounds. Another (White female) is a professor of arts and creativity from Clemson University who has collaborated with First Author (Theresa) on similar projects in the past (cf. Catalano \& Leonard, 2016) and was brought in (through support from the Department of Teaching, Learning and Teacher Education) to help with the dance segment of the workshop but also participated in the research and writing of this paper. The two graduate students (Uma and Alessia) are both current doctoral students of Theresa, and they specialize in multicultural or multilingual education. Uma is an Asian female originally from India, and Alessia is a White female originally from Italy. All of the researchers have lived, taught, and/ or studied in other countries, have rich multilingual repertoires, and several have multilingual children in the US. However, unlike the refugee collaborators in this project, the co-authors' experiences abroad have been mostly voluntarily and hailing from a place of privilege. All members of the research team participated in most of the elements of the workshops and participated in coding and discussion meetings following the workshops. Next, we describe the artsbased workshops.

\subsection{Arts-based workshop}

Before the ACB workshop began, preservice teachers were given information about the Yazidi diaspora, prepared by one of the Yazda members for them. They also had a training/discussion session with a local psychologist on working with people who have experienced trauma, and they had a chance to ask questions about how to avoid triggering trauma and what to do if participants become uncomfortable during this process. The following week (September 5, 2019), the workshop began during the designated class time. First, preservice teachers were broken into groups of 4-5 and sent to six different rooms for pre-workshop discussions which were audio-recorded on the Quick Voice recording app on the research team's phones. Discussions lasted $1 \mathrm{~h}$ each and resulted in $6 \mathrm{~h}$ of recorded data. These discussions involved the researchers asking questions about preconceived notions of immigration, civil discourse, and arts-based education to gauge what teacher learners knew and thought before experiencing 
the workshops. After the discussions, the preservice teachers and research team met the Yazidi collaborators at the UNL museum on campus, and Yazidi collaborators joined the preservice teacher and researcher groups. All project participants were given name tags to wear to aid in learning each other's names.

Before visiting the museum exhibits, the education specialist at the museum prepared students to engage in the art experiences by talking to them about the exhibit "Unquiet Harmony: The Subject of Displacement," which focused on human displacement and featured works from various artists centering on the theme of migration. She explained how the exhibit was created as part of our research project through collaboration with the museum, whose main mission is to serve the university community. She also related the exhibit to the students' study of migration in their class (and how this impacts them as teachers) and prepared them for how to approach the museum experience by first observing the artwork, then describing, and then analyzing it in their groups.

She then divided up project participants into groups and engaged them in exploring and discussing the various elements of the exhibit and reporting on their experiences and reactions to the artwork. The museum exhibit was designed to give teacher learners a new perspective on what they already knew about migration experiences as well as away to understand how people can react to and interpret art differently based on their own backgrounds and lived experiences (see Photos 1 and 2).

After this visit, project participants went into the museum auditorium and had 1 hour to visit with their Yazidi collaborators (one in each group), get to know each other, and ask each other about their experiences and their own migration stories. During this time, most of the Yazidi collaborators took the opportunity to tell their stories related to the ISIS attacks, their families' escapes, and the process of trying to find family and heal from the genocide while preservice teachers asked questions and told their own stories when appropriate. Teacher learners were then asked to think about what more they want to learn from their Yazidi collaborators and in turn, the Yazidi collaborators were asked to think about what they want teacher learners to know about them and their children in order to share with each other the next week. On September 12, 2019, all participants returned 

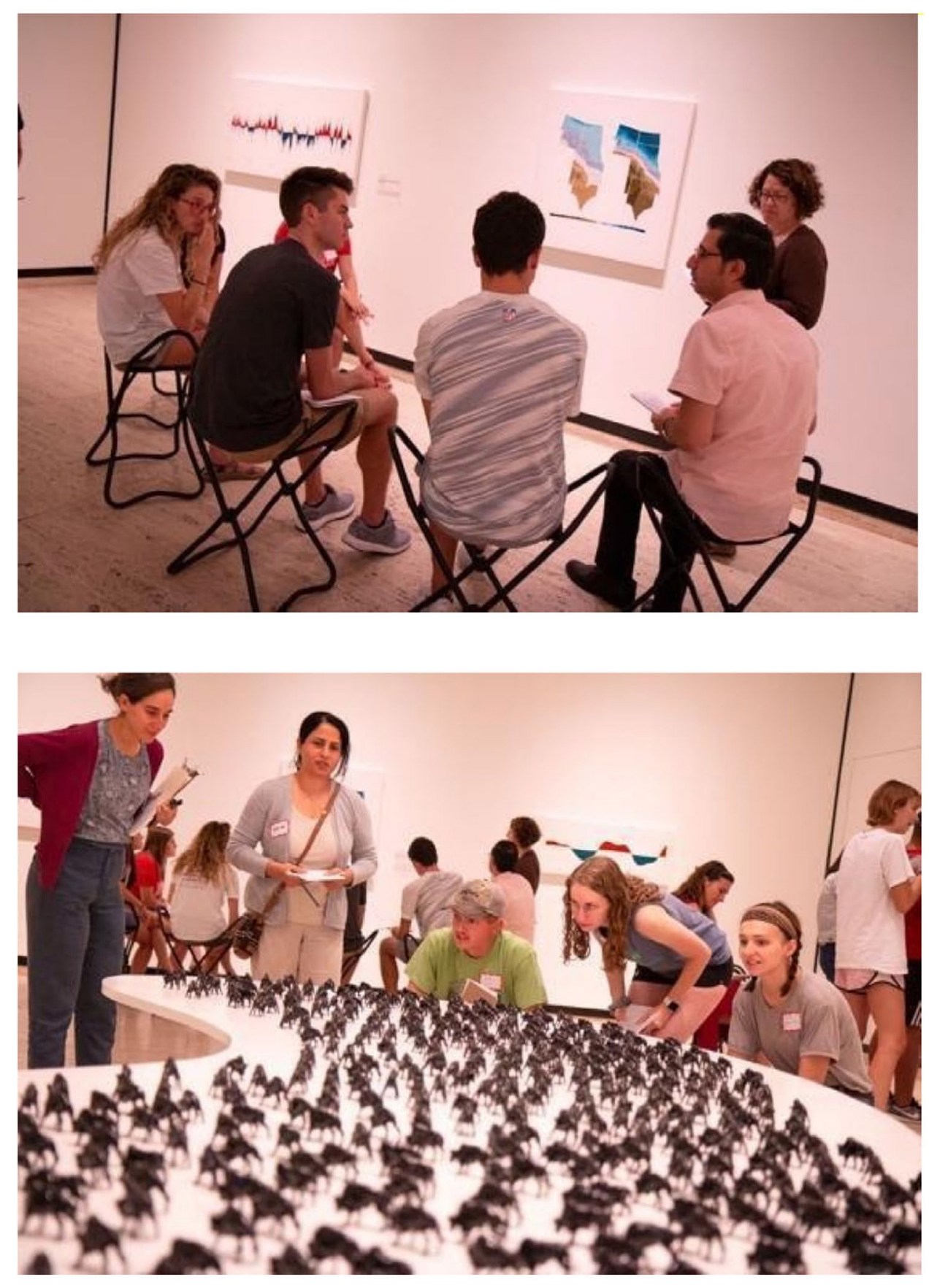

Photos 1, 2. Exploring the exhibit together. * Photos were published with permission from project participants.

to the museum auditorium and began by continuing their conversations from the previous week in their same groups, and reviewing what they had learned from each other so far. 


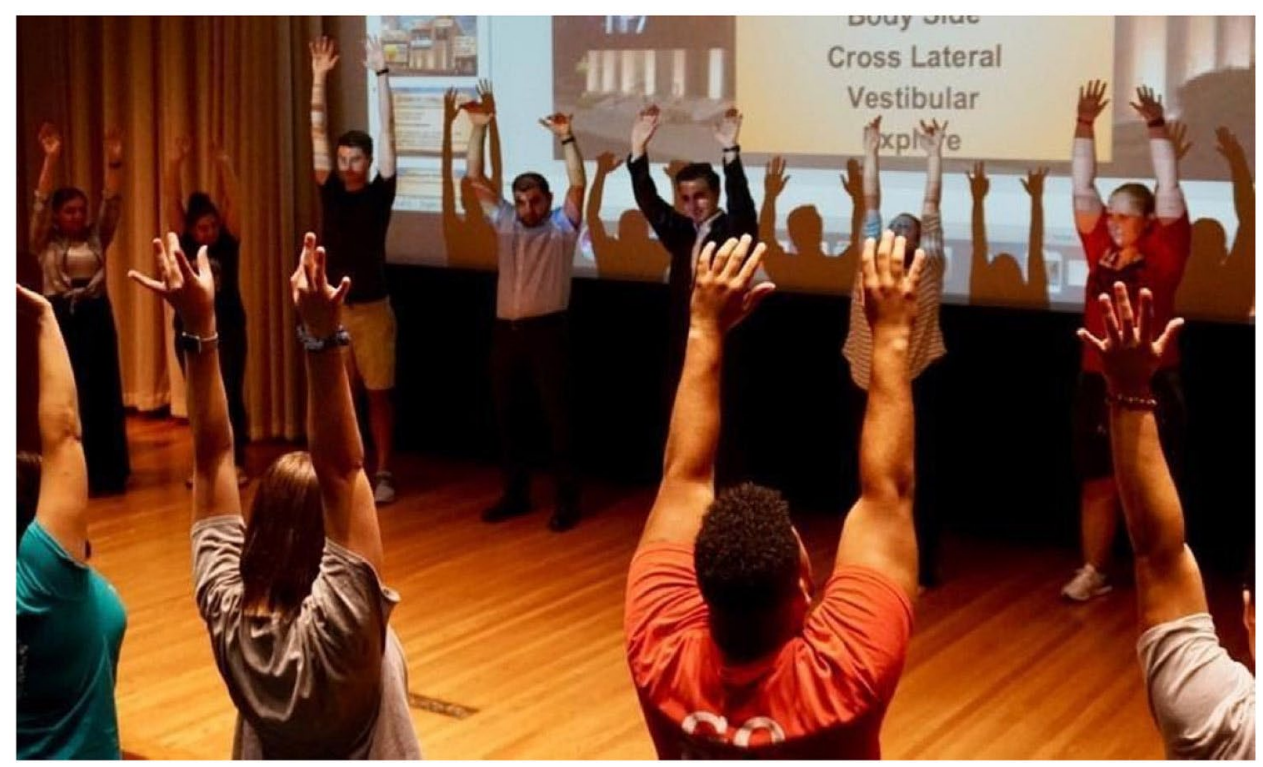

Photo 3. Warm-up in museum auditorium.

Before engaging in the dance part of the workshop, we needed to prepare the project participants to make art with their bodies, and understand what it means to choreograph dance. Many of the students were nervous about (and some even dreaded) this part of the workshop for a variety of reasons. As such, we knew we had to scaffold the experience for them so they would start slowly and participate in dance activities as a whole group first to lessen their anxiety and then explore more complex, small group work, collaboratively choreographing their dance stories. We began this scaffolding with a physical warm-up activity led by Alison (arts and creativity educator) (see Photo 3 ).

They then explored mapping abstract emotions onto their bodies (e.g., show sadness with their arms, show happiness with their index finger) (see Photo 4).

Next, they practiced working with their groups to show emotions with their bodies, and then explored telling stories with their bodies, creating a dance story using creative movement.

Theresa and Alison modeled an example of a dance story inspired by the exhibit, and they also demonstrated how to interpret ideas in both literal (i.e. pantomime, acting out) and abstract ways (i.e. exaggerating, reordering, and repeating). Then everyone reconvened in their original groups and brainstormed parts of their conversations 


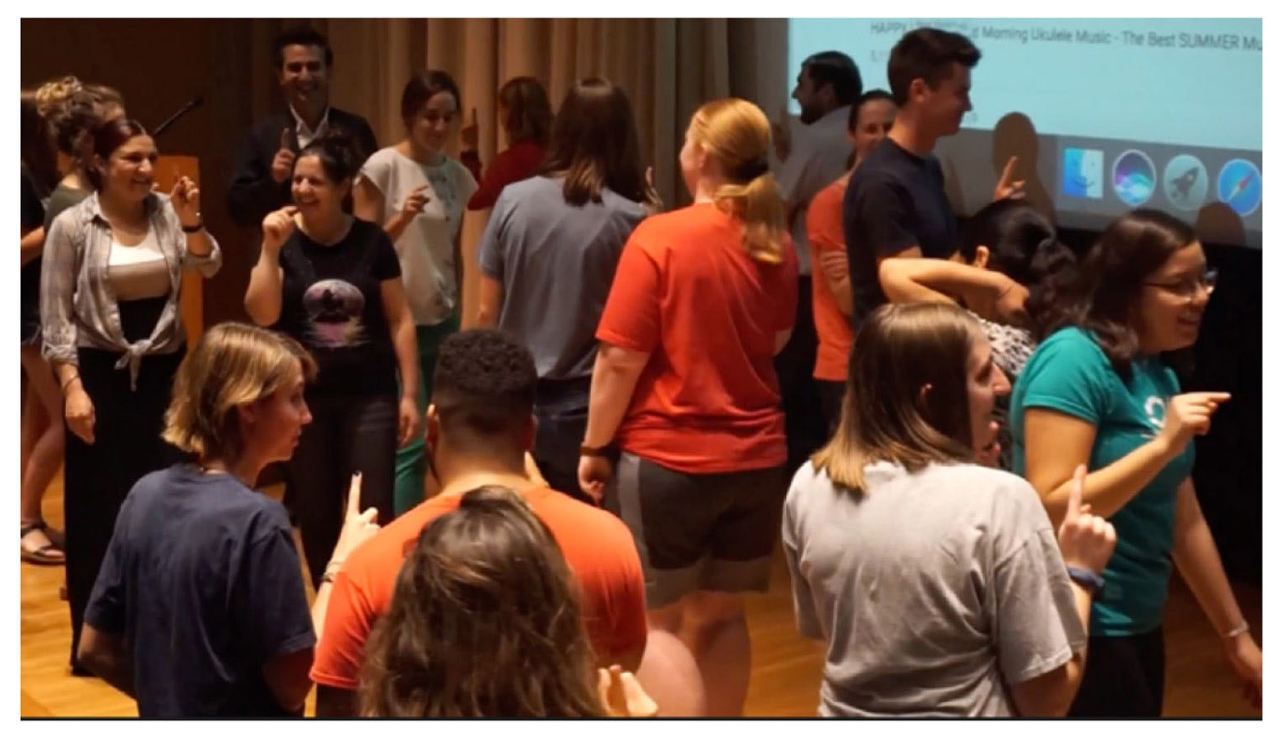

Photo 4. Happiness with your index finger.

and stories that were told in the groups that had moved them, or made them re-think past perceptions or attitudes about immigration. They then began re-creating those salient elements from their conversations into dance stories. All project participants (including the research team) engaged in the dances and performed them for the group, despite the fact that most had no prior dance experience, especially with contemporary dance. Below are a few examples from the dance stories with descriptions of what they were depicting: (see Photos 5-11)

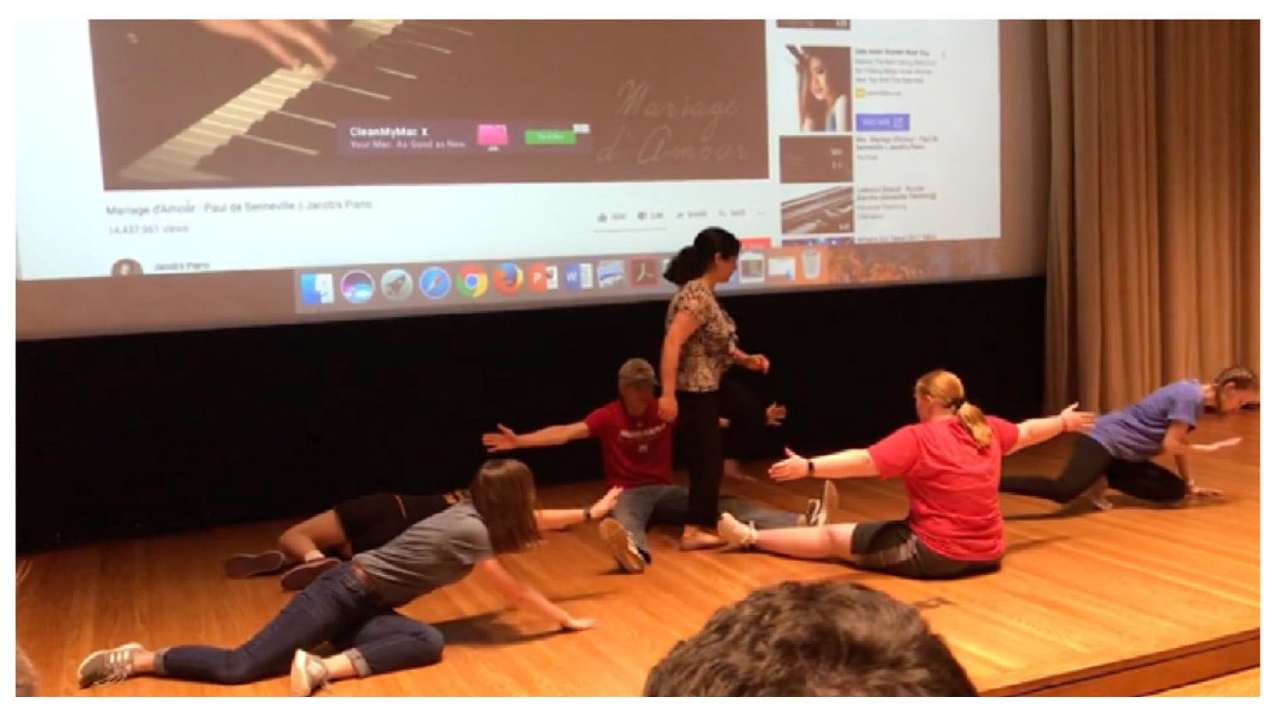

Photo 5. Crossing the bridge to safety. 


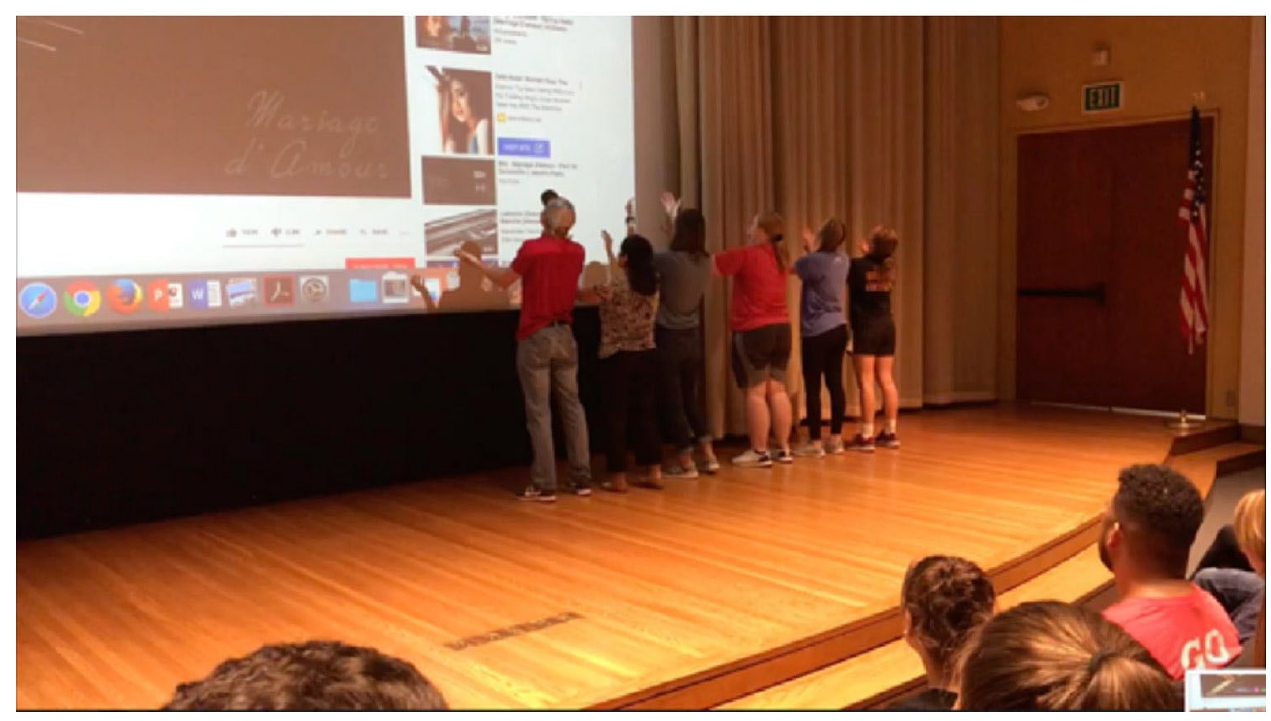

Photo 6. Hope at the end of the journey.

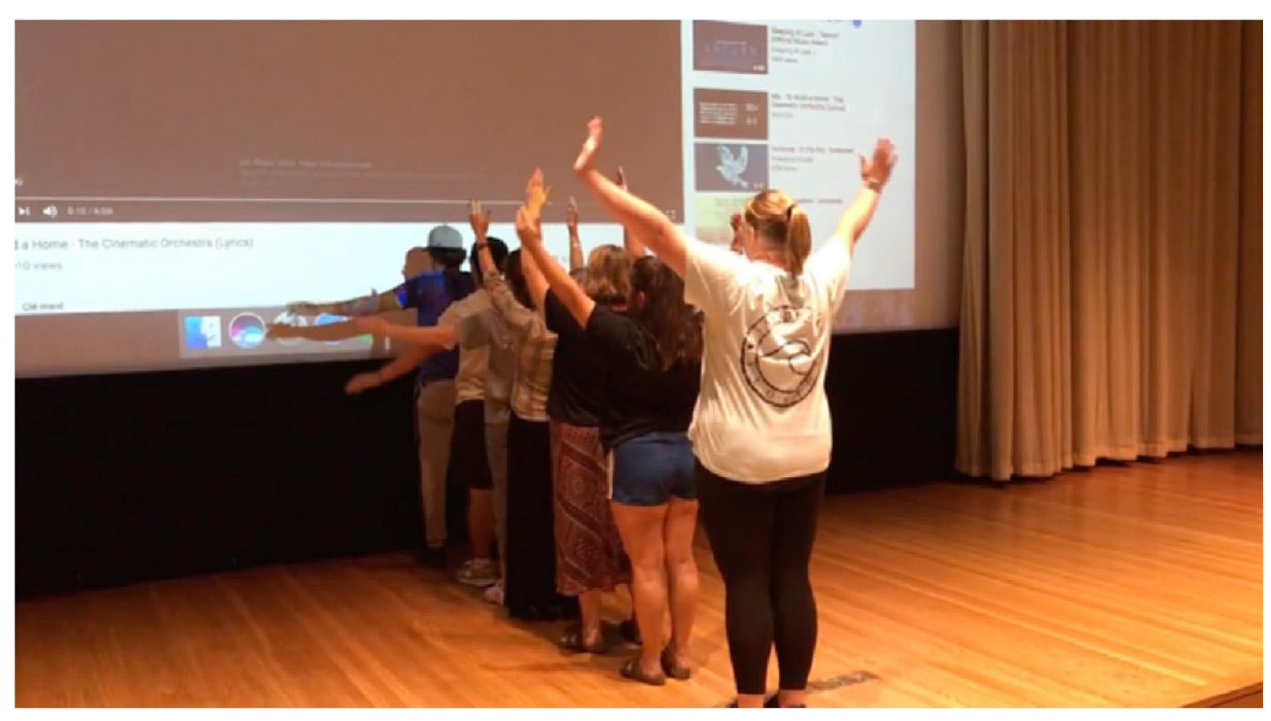

Photo 7. Exploring new cultures.

After each dance was performed, the researcher/teacher educators led a discussion in which project participants described what they saw and what they thought it represented in the story. Then the performers discussed their perceptions, and further explained what they were trying to convey. They talked about the thematic and movement motifs they noticed across the dances. After the discussion, project participants went with their groups and a research team member to 


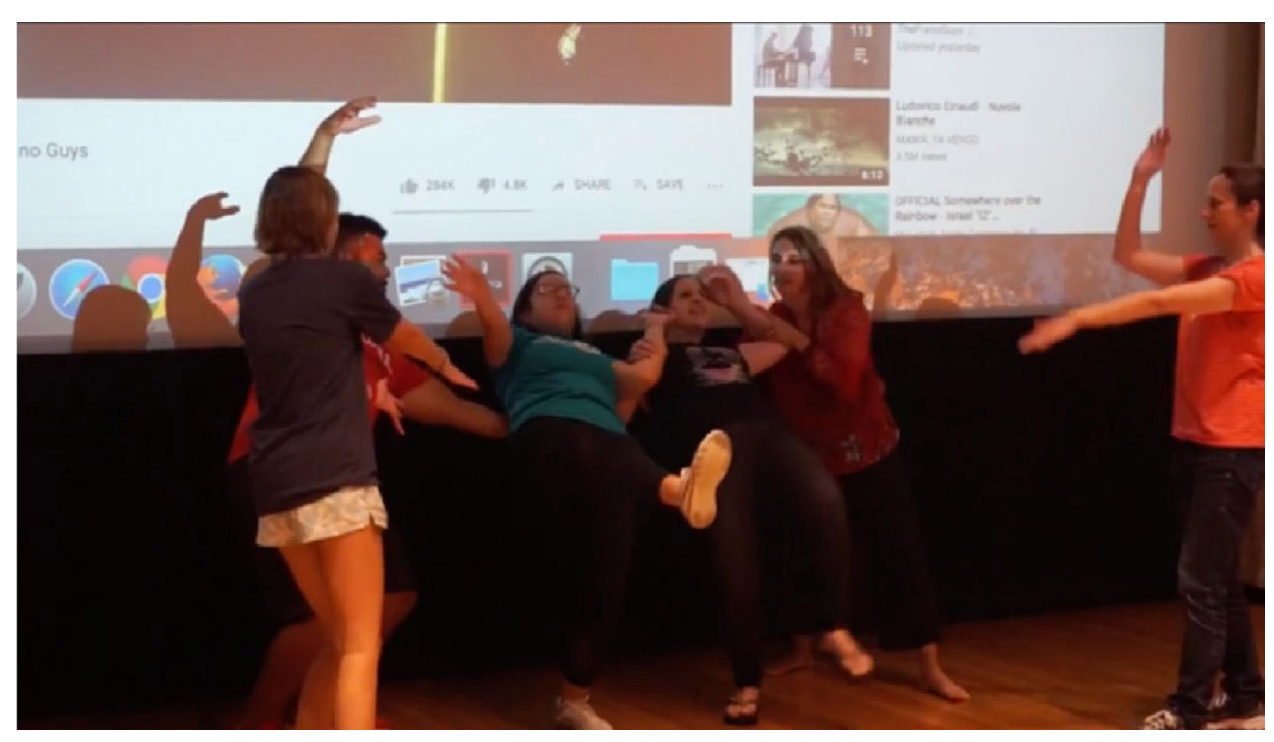

Photo 8. Falling back and being uprooted.

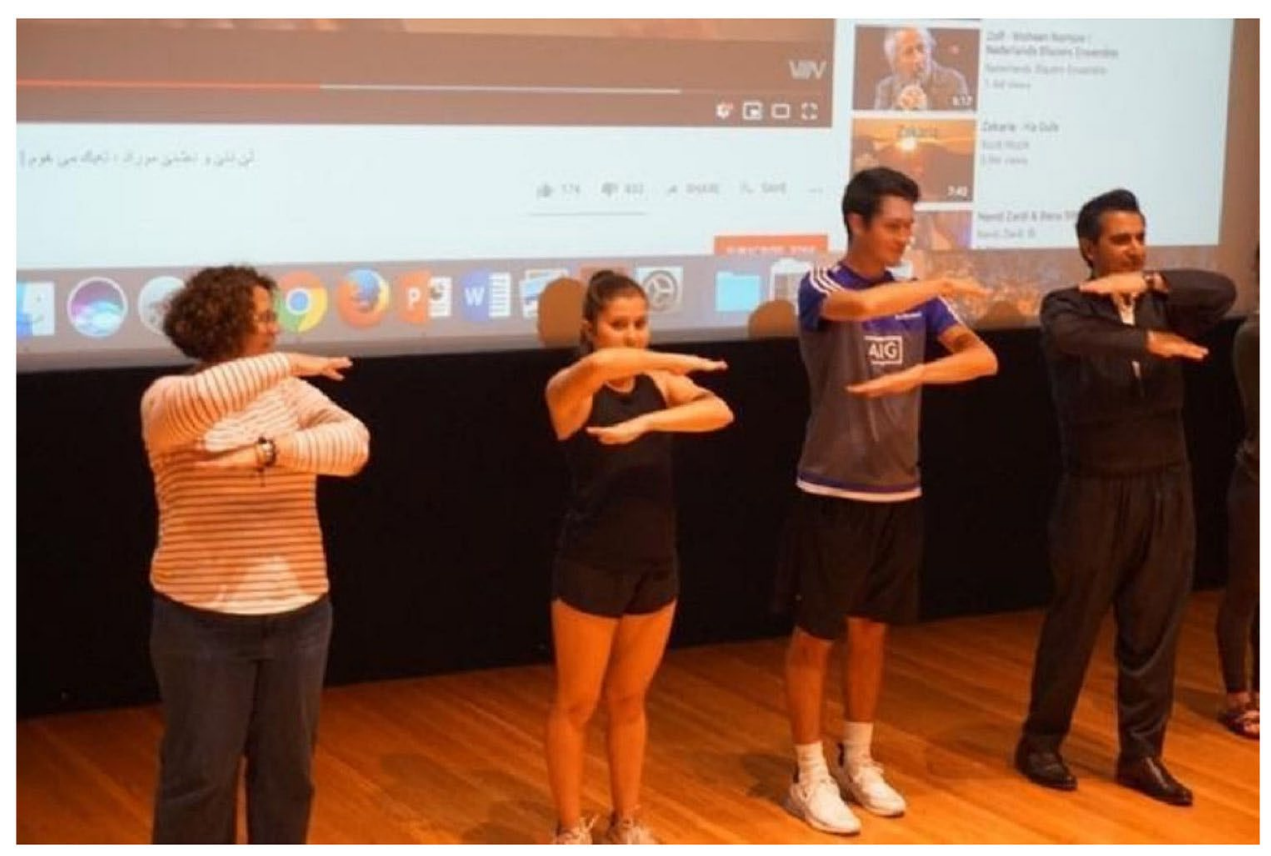

Photo 9. Family separation.

small rooms nearby for post-workshop discussions in which they described their impressions of the workshop, as well as changing ideas related to immigration, civil discourse, and ACB education. Research team members led the discussions beginning with post-workshop 


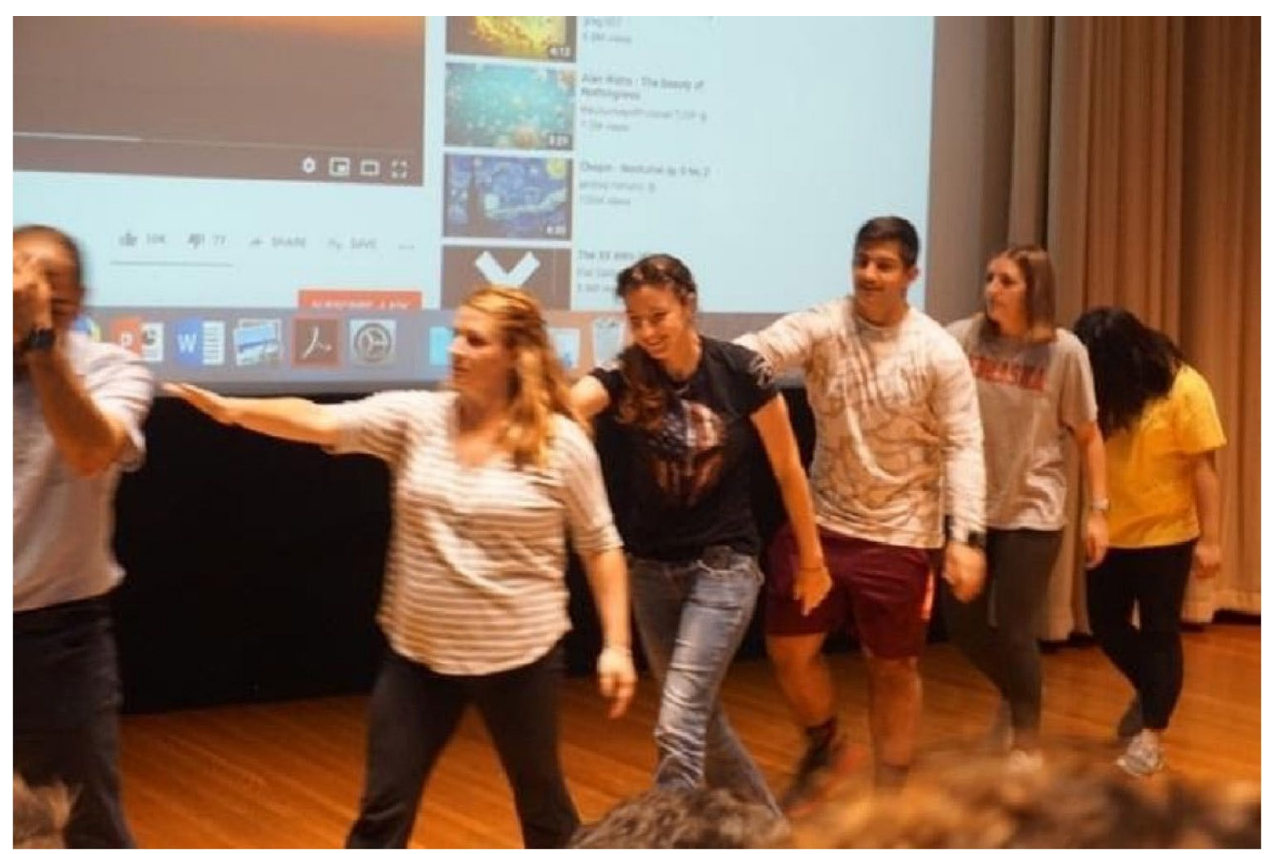

Photo 10. Rescuing people from Mount Sinjar.

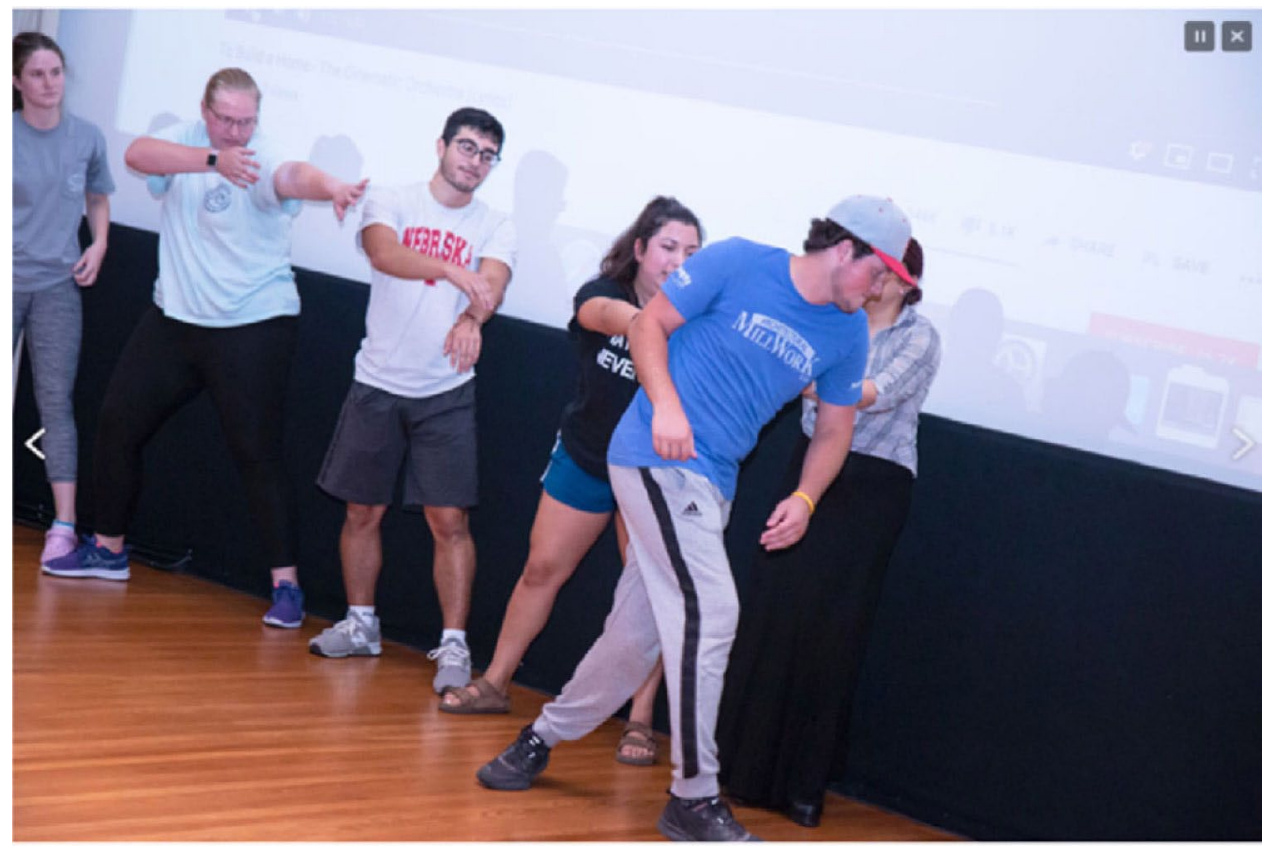

Photo 11. Push and pull of new and existing cultures.

questions listed in Appendix B. Some of the discussion questions led to more open discussions depending on the answers students gave and discussion leaders asked follow-up questions when necessary. These 
discussions lasted 1 hour and resulted in 6 hours of recorded data. The final element of the workshop was the final reflection that the preservice teachers wrote and uploaded to their course management system the week after the workshop on September 19, 2019. Alternatively, Yazidi collaborators preferred to reflect as a group discussion (as opposed to writing), and so they met with the researcher on the same day for 2 hours, and the Theresa asked them similar questions and recorded them with the Quick Voice recorder app. Yazidi collaborators were also invited to member check a draft of this paper once it was written up and to provide feedback on it to the researchers/ teacher educators.

\subsection{Data collection}

Data for this study consisted of 12 hours of pre- and post-group discussion recordings as well as 2 hours of oral reflections from discussions with Yazidi collaborators one week after the workshops. All were recorded on Quick Voice and transcribed using Temi.com. In addition, written reflections from 24 teacher learners which were uploaded by students to the course management system (Canvas) one week after the dance workshop were also used as data.

\subsection{Data analysis}

Transcribed data from the discussion groups and reflections was first coded by Uma and Alessia. They selected all comments in which project participants referred to the arts-based workshop (including dance or visual art) and put them into a file which First Author uploaded to MAXQDA, qualitative software analysis program. A pseudonym list was created and used to replace participant names in the files. Theresa then completed an initial metaphor analysis using MIPVU (Steen et al., 2010) to find metaphors used to talk about the ACB approach used in the study. She used open coding and in-vivo coding to produce 13 initial metaphor categories. She then met with Uma and Alessia to calibrate and re-code the metaphors (after having previously viewed drafts of metaphor charts sent by First Author). During this discussion session, we talked over the metaphor categories and deliberated in terms of what the larger and more overarching metaphors were (e.g., we originally had a metaphor of ACB IS A BRIDGE but then we 
decided together that this was part of the larger JOURNEY metaphor. We deleted some categories or changed their titles, and merged some categories to end up with a final total of eight dominant, secondary, and occasional metaphors. We drew on well known scholars in this area such as Lakoff \& Johnson, and Steen et al. to determine Input Space 2 names. Additionally, we discussed analysis of the metaphors and their contribution to understanding the impact of the arts/community-based experiences on teacher learners and Yazidi collaborators. We also discussed how the metaphors related to our research questions relating to developing interculturality in our teachers, and how the metaphors informed us of this, and First Author took notes from this discussion. We then re-calculated the totals and percentages of the metaphor blends and created Table 1 following Santa Ana's (2002) model of metaphor tabulation. Theresa then began the written analysis using her notes from the discussions with Uma and Alessia to help write the Findings section in which she connected theories related to democratic education/ civil discourse, and the development of interculturality in teachers and the arts. This draft was then enhanced and modified by all other authors using a Google document over a time period of three weeks. Results from this analysis are discussed in the next section.

\section{Findings and discussion}

Table 1 illustrates the dominant, secondary, and occasional metaphor blends found in the data.

Due to the scope of this paper, we will discuss in detail only the dominant and secondary metaphor blends. These metaphors were DANCE AS DIALOG, ACB EDUCATION IS A (DANGEROUS) JOURNEY, and MINDS ARE CONTAINERS: ACB OPENS THEM. The next sections break down these metaphors while exploring what we can learn from them about good intercultural teacher education. For each section, we selected several salient examples that clearly illustrated the metaphors in focus. Interestingly, the majority of metaphor blends found (and as a result, most of our examples) were taken largely from the written reflections and not the discussions, with the exception of a few examples from oral reflections of Yazidi collaborators. This is because the data from the reflections was written data (as opposed to the oral 
Table 1 Metaphor blends with ACB as Input Space 1.

\begin{tabular}{llcr} 
Type & Input Space 2 & Total & Pct. \\
\hline Dominant & $\begin{array}{l}\text { DIALOG } \\
\text { e.g., Dance tells a story and acts like voice }\end{array}$ & 35 & $35 \%$ \\
Secondary & 20 & $20 \%$ \\
& $\begin{array}{l}\text { JOURNEY } \\
\text { e.g., We have to reach the point } \\
\text { MINDS ARE CONTAINERS }\end{array}$ & 16 & $16 \%$ \\
Occasional & $\begin{array}{l}\text { e.g., getting their thoughts out } \\
\text { OBJECT } \\
\text { e.g., I just felt it }\end{array}$ & 8 & $8 \%$ \\
& $\begin{array}{l}\text { VISION } \\
\text { e.g., very vivid in her mind }\end{array}$ & 7 & $7 \%$ \\
& $\begin{array}{l}\text { FORCE } \\
\text { e.g., in a powerful way } \\
\text { CULTIVATION } \\
\text { e.g., they can grow }\end{array}$ & 6 & $6 \%$ \\
EQUALIZER & 5 & $5 \%$ \\
Total & & 3 & $3 \%$ \\
\hline
\end{tabular}

data from recorded discussions) allowing teacher learners more time to reflect, and hence the data was more metaphor rich. This finding (that written data contains more metaphors) aligns with Steen et al. (2010) who note that "within conversation, a relatively small number of words are metaphorically used" (p. 85). In addition, pre-workshop discussions did not focus as much on the arts experience because they had not experienced it yet. Because the post-workshop discussions were held immediately following the workshop, we believe our data from these conversations was not as rich because students were tired from the experience, but also because they had not had enough time to process the experience. Therefore, the data in the written (or oral reflections from Yazidi collaborators) was much more interesting to discuss and useful in answering our research questions, which is why it is featured here.

\subsection{Dance as dialog}

The most dominant metaphor in the data which consisted of 35\% of all metaphors found was DANCE AS DIALOG. What is interesting about this metaphor blend is that among all the different activities included 
in the workshop (e.g., museum exhibit and discussion, conversations with community collaborators), it is the dance that stood out most, and that was mentioned most in terms of its value in teacher education. Below is an example of what the linguistic realization of this metaphor looked like in the data:

It is helpful for students who are in the early stage of acquiring English to participate in arts-based workshops because arts don't require people to use language to communicate what they want to say. We are able to create from what we already know and speak to each other without the use of words. We got to experience this while doing a dance with the Yazidi refugees. (Jessica, reflection, September 19, 2019)

The metaphor blend DANCE AS DIALOG comes from the merging of input spaces containing what we know about dance (we use our bodies, it is for entertainment or expression) and what we know about conversation or dialog (we use our voices to produce words and ideas, we talk to each other with our mouths/tongues). In the case of the blend, when we combine the two input spaces, we end up with our whole bodies as vehicles for reciprocal dialog in which both parties speak in embodied ways, instead of through words. In Jessica's comment above, she notes not only the value of dance as a means of communication (e.g., speak to each other without the use of words), but she acknowledges how these kinds of activities might benefit her own students with immigrant backgrounds. In addition, she recognizes the importance of tapping into prior knowledge in her comment create from what we already know. Interestingly, many of the teacher learners shared that part of why the dance creation was so valuable was because it was something they co-created with their community partners. The fact that students appreciated collaborating and working toward a common goal reminds us of Dewey's theories on the value of extending school to the community, and how one of the goals of education should be "to produce a virtuous, cooperative citizenry" (Proefriedt, 2008. p. 96). Halsey reiterates similar points about collaboration in her example below: 
Even if you don't understand the same language, you can share ideas, beliefs, and experiences through movement. Dance tells a story and acts like voice. In addition to the content to a dance piece, I think that creating collaboration contributes to a community where all ideas are heard. ... A student might not have their own ideas formed in words but may be able to share their thoughts and feelings through dance ... The arts help us better understand ideas and feelings, which is a similar goal of civil discourse. (Halsey, reflection, September 19, 2019)

In this example, dance is personified (e.g. tells a story), revealing the way in which the preservice teachers viewed it as its own creature, valuable in terms of creating a space for everyone to discuss controversial topics (e.g. creating collaboration contributes to a community where all ideas are heard). Democratic deliberation is a dynamic and reciprocal process which should be accessible for all participants (Guttman and Thompson, 2004; Noddings, 2013). As Zeichner et al. (2015) warn, simply putting teacher learners in collaborative situations out in the community does not mean that all collaborators' voices and opinions will be valued and utilized. Rather, "attention to the democratic qualities of collaboration is necessary" (Zeichner et al., 2015, p. 127) and in community-based projects, "community concerns should be visible" in ways that hold power (Calabrese-Barton et al., 2020, p. 2). Halsey's comment recognizes this by noting how the dance played a large role in creating a democratic environment in which everyone's contributions were valued.

The idea of creating a place where project participants could be equal was important to the development of this project, and part of the reason that we researcher/teacher educators all participated in the dances along with our students because in order to make positive social change, we recognized that "we must be willing to change ourselves" (Powers \& Duffy, 2016, p. 71). As we decided on what activities to include in the workshops, we reflected on Gorski's (2008) point about good intentions not being enough. We were also acutely aware of his suggestion that we should avoid requiring "dominated groups to make themselves ever more vulnerable for the educational benefit of the privileged" (p.522). As Halsey's comment (and 
many other examples in the data) shows, we believe that dance was uniquely positioned in our approach to make all participants vulnerable because none of them were dancers, and very few had performed in front of their peers on a stage in front of a large group of people. In addition, the co-creation of the dance pieces made it a true collaboration in which Yazidi collaborators (while still vulnerable to some extent because they were not dancers) had the power in the interactions because they guided the stories and the way in which they were realized through dance. As Dewey (1956/1990) contends, "A society is a number of people held together because they are working along common lines, in a common spirit, and with a reference to common aims". Hence, everyone in this project worked together for a common goal-not just themselves, which created a "sympathetic feeling" or empathy (p. 17). This is something they might not have been able to do (because of their varying English proficiency) had they been asked to only tell their stories verbally. When asked about the value of the dance, Ezdeen confirmed this finding, but also conveyed the healing quality of dance:

So I know probably dance is very important to express your feelings when, when you cannot talk and then there's no one is listening to you. Usually the dance is connected to happiness and joy and to make you happy and feel like you have, you are everything in the world. But when you do express something really sad and you have some memory that is pain and despair, it's kind of, sometimes it's hard. You have to forget these sad moments and try to create a movement and maybe this will express your happiness (Ezdeen, reflection interview, September 19, 2019).

Ezdeen's comment shows what he gained from the experience, and the way in which having a chance to tell people outside his community about what he experienced (and to correct misunderstandings about his community that could lead to further incidents or violence) had healing power for him, something Johanna noted in her comment in the next section. 
5.2. ACB education is a (dangerous) journey

The metaphor blend of ACB EDUCATION IS A (DANGEROUS) JOURNEY draws on the very common way in which teacher learners think about their journey of becoming a teacher, as seen in Gatti \& Catalano (2015). In this blend, the teacher learner has set ideas about what a journey is like (e.g., you move toward a destination, encounter obstacles, have someone to guide you, make choices about the path you take and how you will travel it). This is then blended with concepts related to education, i.e., how teacher learners must work toward graduating and getting a job, having good advisors and cooperating teachers to help them, obstacles or barriers such as not understanding content or financial problems, deciding what to teach and what level, and where to study. When these two input spaces are blended, particularly in thinking about ACB in their teacher education programs (and in their own future teaching), the preservice teachers produced metaphors such as the following:

For instance, the dance workshop allowed us to portray the emotional journey of the Yazidi refugees. (Mackenzie, reflection, September 19, 2019)

Mackenzie's comment reveals how the emotions of the Yazidi collaborators throughout the dance workshop were perceived as a journey that she had a role in portraying to her classmates. That is, there were ups and downs, and there were emotional lows (e.g., being separated from family, violence) and highs (e.g. being reunited with family, saving people on the mountain). From another angle of the JOURNEY metaphor, Dawson combines several blends (e.g., EDUCATION IS A FOUNDATION/EDUCATION IS A DANGEROUS JOURNEY) to show how the increased vulnerability participants felt led them to disrupt their everyday ways of thinking and prepared them to engage in real dialog with each other about immigration.

For me, the dance was a way of breaking down everyone's walls and really getting them out of their comfort zones ahead of the civil discourse. (Dawson, reflection, September 19, 2019) 
The linguistic realization out of their comfort zones exposes an interesting entailment of the metaphor blend. There were 15 tokens found overall in the data that referred to a mental state (lack of comfort) as an actual physical space, and in most cases, teacher learners referred to their initial discomfort in being asked to dance together with their peers and community collaborators. However, most of them noted that it was this discomfort that disrupted their previous ways of thinking so they could move forward on their journey toward becoming a better teacher. This was because their ACB experiences aided in changing previous misconceptions they had about their immigrant students or immigration/refugees in general before participating in the workshop. As Powers and Duffy (2016) note, the objective of these kinds of arts-based learning experiences should not be to make students comfortable. While it is important to relax students in order for them to learn, making students too comfortable could result in not challenging their preconceived notions, and hence it is important to keep a balance between the two. As Gorski (2008) contends, "Authentic intercultural practice is undertaking shifts in consciousness that acknowledge sociopolitical context, raise questions regarding control and power, and inform, rather than deferring to, shifts in practice" (p. 522). This cannot happen unless teacher learners experience some discomfort. Below, Adeline's comment illustrates how because of the possibility of "shifts in practice" participants often viewed their ACB journey as a dangerous one (Gorski, 2008, p. 522):

With dance, you should have your students be formed in groups and create a topic that may be a little controversial but at the end of it, the students will have fun dancing and the story will be safely out to the audience. (Adeline, reflection, September 19, 2019)

Adeline's example shows how the journey of creating and performing a work of art can be scary and risky, especially at the end of it when the stories are carried safely to the audience (e.g., conflict is avoided). This blend treats a story as if it is a concrete object, which in cognitive linguistics is referred to as an ontological metaphor. Ontological metaphors such as this one help us refer to an entity as a substance and thus we can quantify it, and "identify a particular aspect 
of it" but we can also use it to "deal rationally with our experiences" (Lakoff \& Johnson, 1980, p. 26). The example above reveals how Adeline perceives of the re-telling of the stories through dance as a potentially dangerous obstacle in the journey in which there is a risk of people not receiving the stories well or conflict arising because of the controversial nature of the topic (i.e., genocide, ISIS, aid from the US government). This example also shows how critical reflection, which teacher learners were required to do after the workshops and served as part of our data, "can be an arduous task because it forces the individual to ask challenging questions that pertain to one's construction of individuals from diverse racial, ethnic, and cultural backgrounds" (Howard, 2003, p. 198).

In the final example below, Nadia (one of the Yazidi collaborators) explains why the journey of dance ends with civil discourse:

The goal should be between me and you...So [...] we have to reach the point even if we don't agree with each other. Yeah. I mean like these experiences we've been through, if we just kind of go through dancing, through music, I feel like it's going to be even better to do it than to just talk about it. (Nadia, reflection interview, September 19, 2019)

As noted in the DANCE AS DIALOG section, Nadia's comment shows how she perceives the dance as a vehicle for communication in her journey of democratic deliberation and of expressing her story so that she can help teachers to work with students like her own children better. When she says reach a point, she is referring to the way in which dance (and music, which was chosen for each of the dance creations) can move them toward their destination of understanding each other, and being able to talk about their experiences but also toward being better teachers. Furthermore, the way she talks about going through the dance experiences exposes her perception of ACB education as an alternative path in the journey toward civil discourse. We now turn to our final dominant metaphor.

\subsection{Minds are containers: $A C B$ opens them}

This metaphor blend in which the preservice teachers view their minds as a container that can be opened and closed stems from our 
bodily experiences as physical beings in which we are

... bounded and set off from the rest of the world by the surface of our skins, and we experience the rest of the world as outside us. Each of us is a container, with a bounding surface and an in-out orientation. We project our own in-out orientation onto other physical objects that are bounded by surfaces. Thus we also view them as containers with an inside and an outside (Lakoff \& Johnson, 1980, p. 31).

As part of our overall body container, our minds are also seen as containers that can be opened by the tool of $\mathrm{ACB}$, as in this example:

I think that being able to partake in these arts-based events with others, like the Yazidi refugees, sets an example for opening yourself up to something new, doing something uncomfortable and growing together in community through that uncomfortability. (Rylee, reflection, September 19, 2019)

Above, Rylee shows how she perceives ACB to be a tool that opens her up to new ways of thinking. Here again we see the idea of discomfort re-surface, but also the blend of EDUCATION IS CULTIVATION (e.g., growing together), which recognizes the community collaboration as part of the opening up of her mind and developing as a novice teacher. Below, Johanna notices the effect of ACB on her community partners:

Again, I was astounded to see how these experiences helped the Yazidi people to open up and perhaps heal some of that trauma. I had never imagined that a simple dance would be able to help so many people connect to such an important, traumatic part of their lives. (Johanna, reflection, September 19, 2019)

Here Johanna connects the dancing with helping Yazidi people to open up, meaning to share painful stories as part of their healing. She also reveals her discovery that not only could the activities be helpful for teacher learners to become better teachers, but that a simple dance could be a powerful force for the Yazidi collaborators as well. In particular, the expression simple dance is useful in understanding the 
way in which Johanna has changed her previous conception of education in the sense that she believed it needed to be complex, difficult or multi-layered. Instead, she has come to realize that seemingly simple tools (like movement) can be mighty in terms of shaping the way students learn and think. In this final example, Emma reports the way in which the activities made her aware of the experiences her future refugee students might have:

The main aspect of my group's interaction with [Nadia] that stands out the most in my mind was that she wanted us to focus on the vivid emotions she remembered experiencing when crossing the bridge during her escape .... I learned so much from the details that [Nadia] shared with us as we were planning our dance and from when we were analyzing the glass bison piece in the Sheldon. Her unique perspective taught me that every detail in a story, dance, or piece of art has meaning. My group's conversation at the end of the last workshop would not have been as deep or meaningful if it weren't for the workshops. In other words, just like the dance activity opened my mind to the experiences of some Yazidi refugees in $X$, a similar activity could help students understand where other people's opinions are coming from, and afterwards they would be more likely to take part in discourses that are respectful and civil. (Emma, reflection, September 19, 2019)

This comment informs our understanding of the value of ACB in a number of ways. First, through the MINDS ARE CONTAINERS blend, Emma shows how much knowledge she has gained in terms of understanding what her students with immigrant backgrounds experience, and "recognizing how community perspectives matter" (CalabreseBarton et al., 2020, p. 9). In addition, she engages in the "high leverage practice" (Calabrese-Barton et al., 2020, p. 2) of learning about her students through the stories of her Yazidi collaborator, and in the process, avoid "creating stereotypical profiles of students that may only do more harm than good" (Howard, 2003, p. 201). From her time creating the dance with Nadia, she was able to visually imagine the way that Nadia felt (e.g., vivid emotions) as she escaped to the bridge (see Photo 5), and how her memory of her people's desperate escape 
to Sinjar mountain when ISIS attacked them was jostled at the site of the bison exhibit (see Photo 2). Emma explains that without participating in these things together in ACB education with Nadia, her experiences would not have been as deep (a spatial metaphor as well) or meaningful.

\section{Conclusion}

Findings from this study illustrate how ACB education pushes back against "test-based educational culture" (Oreck, 2004, p. 67) by creating spaces in which teacher learners can notice and learn from community wisdom (Calabrese-Barton et al., 2020). In this way they are able to develop interculturality in "small, incremental moves" (Powers \& Duffy, 2016, p. 71) such as when they realized that having some degree of discomfort in intercultural situations is not only normal, but desirable. In addition, our findings showed how the body can be an important tool in intercultural communication and the importance of letting all participants have a voice and listen to each other. Lastly, our study revealed how teacher learners realized the value of understanding experiences from the perspectives of others, which creates empathy, and leads them on a pathway to civil discourse about contentious topics. The ACB approach in this paper allowed us to create "safe enough spaces" where our students could grapple with the complexity of teaching and learning in order to be better prepared to work with students with immigrant/refugee backgrounds, like the children of our Yazidi collaborators. The findings of this paper also show how metaphor analysis can contribute to our understanding of the experiences of preservice teachers and the way in which we can continue to improve their education by helping them "to acquire the breadth of knowledge that will enable them to stretch their disciplines from within" (Noddings, 2013, p. 73) and the skills needed for effectively teaching the diverse populations represented in today's classrooms.

In terms of limitations to our study, we wished we had had more time to truly develop further our relationships between the collaborators and preservice teachers (and researchers/teacher educators) and for project participants to ask more questions and learn more about 
each other. Workshop time always felt rushed as we had so much we needed to do, but we could only do it in the set class time period. On the other hand, we were mindful of taking up the time and resources of our community collaborators and so it is important for teacher educators to keep a balance between having enough time to interact and creating a project in which all participants can benefit and not asking community collaborators to sacrifice in terms of personal time. Finally, it could be argued that a limitation of this study is the strong belief in the value of arts education that we (the research team) held before creating and participating in the arts-based workshops, which could be interpreted as the positive findings being a foregone conclusion. That is, we created the workshops already believing in their power, and knowing that something good would probably happen because of them. However, we believe our findings were not a matter of course because the workshop yielded results we had not anticipated and this impact was greater than what we had imagined initially. None of us predicted the intense emotional impact of the experience on teacher learners, the ways in which intercultural skills developed through the experience, or the rich understanding of refugee-background students that the preservice teachers gained.

To conclude, we believe that aesthetic activities such as those in our workshop (regardless of what content area they are from) help teacher learners begin to see connections between research and practice and we agree with Zeichner et al. (2016) that as we move forward in teacher education, it is important to continue to explore how to "work in solidarity with local communities" (p. 288). Furthermore, cocreation in arts-based projects where interdependence and cooperation are centered present a promising pathway toward contributing to social change and the creation or continuation of a democratic society.

Acknowledgments The authors would like to thank the journal's editors and anonymous reviewers for their excellent suggestions and comments which helped improve our paper. In addition, we are grateful for the Sheldon Museum of Art who helped create this experience and house our project, and for our funders, Humanities Nebraska and the Department of Teaching, Learning and Teacher Education who believed in our project and helped us see it to fruition. We would also like to acknowledge the Nebraska Center for Research on Children, Youth, Families and Schools for helping us prepare our grant proposal. Finally, we would like to thank our amazing students for being "open" to trying something new, believing in the power of the arts in education, and allowing us to explore its potential with them. 
Funding The authors received financial support from Humanities Nebraska and the Department of Teaching, Learning and Teacher Education at the University of Nebraska-Lincoln for this research. In addition, they received administrative support from the Nebraska Center for Research on Children, Youth, Families and Schools.

Competing interest The authors declared no potential conflicts of interest with respect to the research, authorship, and publication of this article.

\section{Appendix A. Pre-Workshop Discussion Groups: (Week 1)}

1) What words come to mind when you think of immigration?

2) What do you know about immigration issues in Nebraska?

3) What are the major problems related to immigration in our state?

4) What words come to mind when you think of immigration?

5) Is immigration political? Why or why not?

6) What do you want to know about immigration?

7) Do you have any experience working with or interacting with students or people of immigrant backgrounds?

8) The United Nations refugee agency (UNHCR) defines refugees as those "forced to flee to save their lives or preserve their freedom" whereas 'migrant' (or immigrant) describes any person who moves, usually across an international border, to join family members already abroad, to search for a livelihood, to escape a natural disaster, or for a range of other purposes" (from the UNHCR handbook found at https://emergency.unhcr.org/entry/250459/migrant-definition ).

Keeping this in mind, what interactions have you had with refugees or immigrants/migrants before?

9) Do you consider yourself a refugee or im/migrant? Do you know anyone in your family who has been internally or externally displaced?

10) Do you think it's important to know about immigration issues as a teacher in Nebraska?

11) What do you know about arts-based education?

12) Have you ever tried arts-based education in any of your teaching or learning so far? Describe what you have done and your thoughts about the activities.

13) What do you think about the current political environment in the United States?

14) What does the term "civil discourse" mean to you?

15) We define civil discourse as "engaging in discourse in order to increase understanding" or "engagement in conversation in which there is a 
mutual airing of views without rancor”. Do you think engaging in civil discourse is an important element of your teaching? Why or why not?

16) What do you think would increase civil discourse in your classes and in the world as a whole?

17) Do you think that arts-based education might be a way to increase civil discourse? If so, how could this be done?

\section{Appendix B. Post-Workshop Discussion Groups: (Week 2)}

1) What did you learn about immigration in the workshops?

2) What are the major problems related to immigration in our state?

3) What do you think is important for teachers to know about immigration or immigrants?

4) What do you think is a problem with our current immigration system?

5) What do you think immigrants/refugees in Nebraska need?

6) Is language important when discussing contentious issues such as immigration? Why or why not? What are the consequences of language on the daily lives of migrants in Nebraska?

7) What words to you think of when you think of immigration? Are any of these words different from the ones you mentioned at the beginning of the workshop?

8) Is immigration political?

9) What is the connection between the language used to talk about immigration and immigration policies?

10) How has the media influenced the way you understand immigration issues?

11) As a refugee/immigrant, how has the media or language used in public circles to talk about immigration influenced your life?

12) (to Yazidi participants) What do you want UNL students and future teachers to know about you? What do you want them to know about teaching Yazidi students?

13) (to UNL participants) What do you want Yazidi families and other refugee/immigrant families to know about you as a teacher?

14) Do you think this conversation counts as civil discourse? Why or why not?

15) Do you think you could have had this conversation before participating in the exhibit and/or the dance workshops?

16) What did the dance stories do for you in terms of creating new understanding about immigration issues? 


\section{References}

A Diaspora Is Born in Nebraska. (2017, December 29). https://jewishjournal.com/ cover_story/228865/diaspora-born-nebraska/ (Accessed 11 March 2020).

Bigelow, M. (2018). Afterword. In S. Shapiro, R. Farrelly, \& M. J. Curry (Eds.), Educating refugee-background students: Critical Issues and dynamic contexts (pp. 256-259).

Bennett, M. M. (2008). Understanding the students we teach: Poverty in the classroom. The Clearing House: A Journal of Educational Strategies, Issues and Ideas, 81(6), 251-256. https://doi.org/10.3200/TCHS.81.6.251-256

Bullough, R. V. (1991). Exploring personal teaching metaphors in preservice teacher education. Journal of Teacher Education, 42(1), 43-51. https://doi.org/1 0.1177/002248719104200107

Calabrese-Barton, A., Tan, E., \& Birmingham, D. J. (2020). Rethinking highleverage practices in justice-oriented ways. Journal of Teacher Education, 1, 18.

Cameron, L. (2002). Metaphors in the learning of science: A discourse focus. British Educational Research Journal, 28(5), 673-688. https://doi.org/10.1080/ 0141192022000015534

Catalano, T., Reeves, J., \& Wessels, S. (2018). The soccer field, it has dirt: A critical analysis of teacher learners in contact with emergent multilingual students. Critical Inquiry in Language Studies, 15(1), 1-20.

Catalano, T., \& Leonard, A. (2016). Moving people and minds: Dance as a vehicle of democratic education. Education, Citizenship and Social Justice, 1-22. https://doi.org/10.1177/1746197915626082

Catalano, T. (2016). Talking about global migration: Implications for language teaching series: New Perspectives in Language and Education. In Bristol, UK: Multilingual Matters.

Cochran-Smith, M., \& Lytle, S. (2009). Inquiry as stance: Practitioner research for the next generation. New York, NY: Teachers College Press.

Coffey, S. (2015). Reframing teachers' language knowledge through metaphor analysis of language portraits. The Modern Language Journal, 99(3), 500-514. https://doi.org/10.1111/modl.12235

Cooper, J. E. (2007). Strengthening the case for community-based learning in teacher education. Journal of Teacher Education, 58(3), 245-255. https://doi. org/10.1177/0022487107299979

Catalano, T., \& Fielder, G. E. (2018). European Spaces and the Roma: Denaturalizing the naturalized in online reader comments. Discourse \& Communication, 12(3), 240-257.

Deardorff, D. K. (2006). Identification and assessment of intercultural competence as a student outcome of internationalization. Journal of Studies in International Education, 10(3), 241-266. https://doi.org/10.1177/1028315306287002

Dewey, J. (1934/2005). Art as experience. London: Penguin.

Dewey, J. (1956/1990). The school and society: The child and the curriculum. Chicago, IL: The University of Chicago Press. 
Fauconnier, G., \& Turner, M. (1996). Blending as a central process of grammar. In A. E. Goldberg (Ed.), Conceptual structure, discourse and language (pp. 113130). Stanford: CSLI Publications.

Gay, G. (2010). Culturally responsive teaching. Multicultural education series (2nd ed.). New York, NY: Teachers College Press.

Gatti, L., \& Catalano, T. (2015). The business of learning to teach: A critical metaphor analysis of one teacher's journey. Teaching and Teacher Education, 45, 149-16o.

Gonzalez, N., Moll, L. C., \& Amanti, C. (Eds.). (2005). Funds of knowledge. New York, NY.

Guttman, A., \& Thompson, D. (2004). Why deliberative democracy? Princeton: Princeton University Press.

Hajisoteriou, C., \& Angelides, P. (2017). Collaborative art-making for reducing marginalisation and promoting intercultural education and inclusion. International Journal of Inclusive Education, 21(4), 361-375. https://doi.org/10. 1080/13603116.2016.1197321

Hanley, M. S. (2013). Introduction: Culturally relevant arts education for social justice. In M. S. Hanley, G. L. Sheppard, G.W. Noblit, \& T. Barone (Eds.), Culturally relevant arts education for social justice: A way out of no way (pp. 1-11). London: Routledge.

Howard, T. C. (2003). Culturally relevant pedagogy: Ingredients for critical teacher reflection. Theory into practice, 42(3), 195-202.

Hunt, D. E. (1987). Beginning with ourselves in practice, theory, and human affairs. Cambridge, MA: Brookline Books.

Kok, S., \& Bublitz, W. (2011). Conceptual blending, evaluation and common ground: George W. Bush and Saddam as friend or foe. Windows to the Mind: Metaphor, Metonymy and Conceptual Blending, 48, 291-310.

Ladson-Billings, G. (2009). The dreamkeepers: Successful teachers of African American children. San Francisco, CA: Jossey-Bass.

Lakoff, G., \& Johnson, M. (1980). Metaphors we live by. Chicago: University of Chicago Press.

Leclerq, J. M. (2003). Facets of interculturality in education. Strasbourg: Council of Europe Publishing.

Leong, S. (2014). Community-based arts and education in partnership. In M. Fleming, L. Bresler, \& J. O’Toole (Eds.) The Routledge International Handbook of the Arts and Education (pp. 283-294). London and New York: Routledge.

Levin, T., \& Wagner, T. (2006). In their own words: Understanding student conceptions of writing through their spontaneous metaphors in the science classroom. Instructional Science, 34(3), 227-278. https://doi.org/10.1007/ S11251-005-6929-X

Lincoln, Nebraska Population. (2020). State population 2020 (demographics, maps, graphs). https://worldpopulationreview.com/us-cities/ lincoln-ne-population

Lustig, M. W., Koester, J., \& Halualani, R. (2006). Intercultural competence: Interpersonal communication across cultures. Pearson/A and B. 
Martínez, M. A., Sauleda, N., \& Huber, G. L. (2001). Metaphors as blueprints of thinking about teaching and learning. Teaching and Teacher Education, 17(8), 965-977. https://doi.org/10.1016/S0742-051X(01)00043-9

Miller, S. I., \& Fredericks, M. (1988). Uses of metaphor: A qualitative case study. International Journal of Qualitative Studies in Education, 1(3), 263-272.

Munby, H. (1986). Metaphor in the thinking of teachers: An exploratory study. Journal of Curriculum Studies, 18(2), 197-209. https://doi. org/10.1080/0022027860180209

Niebert, K., Marsch, S., \& Treagust, D. F. (2012). Understanding needs embodiment: A theory- guided reanalysis of the role of metaphors and analogies in understanding science. Science Education, 96(5), 849-877. https://doi.org/10.1002/sce.21026

Nieto, S. (2000). Placing equity front and center: Some thoughts on transforming teacher education for a new century. Journal of Teacher Education, 51(3), $180-187$.

Noddings, N. (2013). Education and democracy in the 21st century. New York; London: Teachers College Press.

O'Farrell, 1., (2015). Arts education as a bridge to cultural understanding. In Fleming, M.L. Bresler, \& J. O’Toole (Eds.), The Routledge International Handbook of the Arts and Education (pp. 371-377). London; Routledge.

Oreck, B. (2004). The artistic and professional development of teachers: A study of teachers' attitudes toward and use of the arts in teaching. Journal of Teacher education, 55(1), 55-69.

Osei-Kofi, N. (2013). Exploring arts-based inquiry for social justice in graduate education. In M. S. Hanley, G. L. Sheppard, G. W. Noblit, \& T. Barone (Eds.), Culturally relevant arts education for social justice: A way out of no way (pp. 130-140). London: Routledge.

Perry, L. B., \& Southwell, L. (2011). Developing intercultural understanding and skills: Models and approaches. Intercultural Education, 22(6), 453-466. https://doi.org/10.1080/14675986.2011.644948

Phelan, H., \& Nunan, M. (2018). To write or not to write? The contested nature and role of writing in arts practice research. Journal of Research Practice, 14(2). M3-M3.

Powers, B., \& Duffy, P. B. (2016). Making invisible intersectionality visible through theater of the oppressed in teacher education. Journal of Teacher Education, 67(1), 61-73. https://doi.org/10.1177/0022487115607621

Proefriedt, W. A. (2008). High expectations. The cultural roots of standards reform in American education. New York, NY: Teachers College Press.

Provenzo, E. F., Jr., McCloskey, G. N., Kottkamp, R. B., \& Cohn, M. M. (1989). Metaphor and meaning in the language of teachers. Teachers College Record, 9o(4), 551-573.

Routledge Gorski, P. C. (2008). Good intentions are not enough: A decolonizing intercultural education. Intercultural Education, 19(6), 515-525. https://doi. org/10.1080/14675980802568319 
Russell, T., \& Johnston, P. (1988, April 5-9). Teachers learning from experiences of teaching: Analyses based on metaphor and reflection. In [Paper presentation], annual meeting of the American educational research association, New Orleans, LA, United States.

Ryan, P. M. (1996). Sociolinguistic goals for foreign language teaching and teachers' metaphorical images of culture 1. Foreign Language Annals, 29(4), 571-586. https://doi.org/10.1111/j.1944-9720.1996.tbo1268.x

Santa Ana, O. (2002). Brown tide rising: Metaphors of Latinos in contemporary American public discourse. University of Texas Press.

Sharkey, J., Clavijo-Olarte, A., \& Ramírez, L. M. (2016). Developing a deeper understanding of community-based pedagogies with teachers: Learning with and from teachers in Colombia. Journal of Teacher Education, 67(4), 306-319. https://doi.org/10.1177/0022487116654005

Steen, G. J., Dorst, A. G., Herrmann, B. J., Kaal, A. A., Krennmayr, T., \& Pasma, T. (2010). A Method for linguistic metaphor identification. From MIP to MIPVU. Amsterdam/ Philadelphia: John Benjamins. https://doi.org/10.1075/celcr.14

Turner, M. (2014). The origin of ideas: Blending, creativity, and the human spark. Oxford: Oxford University Press.

Zeichner, K. (2011). Teacher education for social justice. In M. Hawkins (Ed.), Bilingual education and bilingualism: Social justice language teacher education (pp. 7-22). Bristol, UK: Channel Press.

Zeichner, K., Bowman, M., Guillen, L., \& Napolitan, K. (2016). Engaging and working in solidarity with local communities in preparing the teachers of their children. Journal of Teacher Education, 67(4), 277-290. https://doi. org/10.1177/0022487116660623

Zeichner, K., Payne, K. A., \& Brayko, K. (2015). Democratizing teacher education. Journal of Teacher Education, 66(2), 122-135. https://doi. org/10.1177/0022487114560908

Zhang, F., \& Hu, J. (2009). A study of metaphor and its application in language learning and teaching. International Education Studies, 2(2), p. 77. https://doi. org/10.5539/ies.v2n2p77

Zheng, H. B., \& Song, W. J. (2010). Metaphor analysis in the educational discourse: A critical review. Online Submission, 8(9), 42-49. 